\title{
Mechanical Properties of Simulated Mars Materials- Gypsum-Rich Sandstones and Lapilli Tuff
}

Open-File Report 2013-1242 


\section{Mechanical Properties of Simulated Mars Materials- Gypsum-Rich Sandstones and Lapilli Tuff}

By Carolyn Morrow, David Lockner, and Chris Okubo

Open-File Report 2013-1242

U.S. Department of the Interior

U.S. Geological Survey 


\section{U.S. Department of the Interior \\ SALLY JEWELL, Secretary}

\section{U.S. Geological Survey \\ Suzette M. Kimball, Acting Director}

U.S. Geological Survey, Reston, Virginia: 2013

For more information on the USGS-the Federal source for science about the Earth, its natural and living resources, natural hazards, and the environment-visit http://www.usgs.gov or call 1-888-ASK-USGS

For an overview of USGS information products, including maps, imagery, and publications, visit $h$ ttp://www.usgs.gov/pubprod

Suggested citation:

Morrow, C., Lockner, D., and Okubo, C., 2013, Mechanical properties of simulated Mars materials-Gypsum-rich sandstones and lapilli tuff: U.S. Geological Survey Open-File Report 2013-1242, 11 p., http://dx.doi.org/10.3133/ofr20131242.

Any use of trade, firm, or product names is for descriptive purposes only and does not imply endorsement by the U.S. Government.

Although this information product, for the most part, is in the public domain, it also may contain copyrighted materials as noted in the text. Permission to reproduce copyrighted items must be secured from the copyright owner. 


\section{Contents}

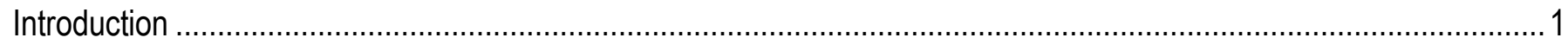

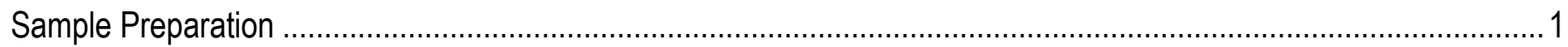

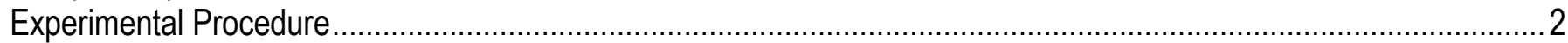

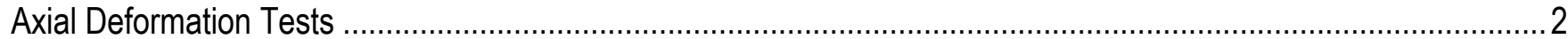

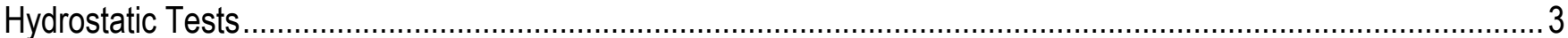

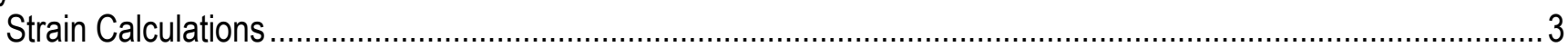

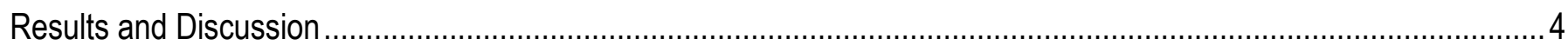

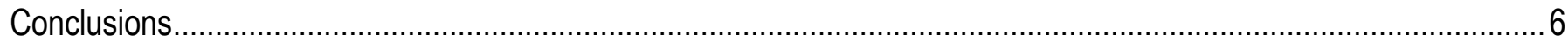

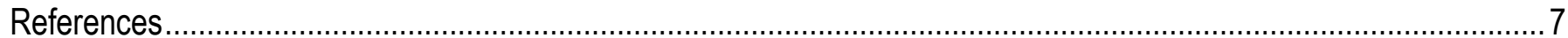

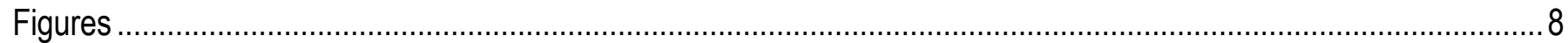

\section{Figures}

Figure 1. Differential stress as a function of axial displacement for A, 100-series samples; B, 200-series samples;

C, 300-series samples; and D, lapilli tuff.

Figure 2. Volumetric strain as a function of effective pressure for the four sample types.

Figure 3. Mean effective stress as a function of porosity change for both deformation tests and hydrostatic loading of the 100 series samples......

Figure 4. Young's Modulus as a function of effective pressure for three sample types.

Figure 5. Poisson's Ratio for selected 300 series and lapilli tuff samples

Figure 6. Bulk Modulus of the four sample types as a function of the average effective pressure during the measurement.

\section{Tables}

Table 1. Physical Properties of Samples 


\title{
Mechanical Properties of Simulated Mars Materials: Gypsum-Rich Sandstones and Lapilli Tuff
}

\author{
By C. Morrow, D. Lockner, and C. Okubo
}

\section{Introduction}

Observations by the Mars Exploration Rover (MER) Opportunity, and other recent studies on diagenesis in the extensive equatorial layered deposits on Mars, suggest that the likely lithologies of these deposits are gypsum-rich sandstones and tuffaceous sediments (for example, Murchie and others, 2009; Squyres and others, 2012; Zimbelman and Scheidt, 2012). Of particular interest is how the diagenesis history of these sediments (degree of cementation and composition) influences the strength and brittle behavior of the material. For instance, fractures are more common in lower porosity materials under strain, whereas deformation bands, characterized by distributed strain throughout a broader discontinuity in a material, are common in higher porosity sedimentary materials. Such discontinuities can either enhance or restrict fluid flow; hence, failure mode plays an important role in determining the mechanics of fluid migration through sediments (Antonellini and Aydin, 1994; 1995; Taylor and Pollard, 2000; Ogilvie and Glover, 2001). As part of a larger study to characterize processes of faultcontrolled fluid flow in volcaniclastic and gypsum-rich sediments on Mars, we have completed a series of laboratory experiments to focus on how gypsum clast content and degree of authigenic cementation affects the strength behavior of simulated Mars rocks. Both axial deformation and hydrostatic pressure tests were done at room temperature under dry conditions.

\section{Sample Preparation}

Four types of simulated Mars materials were tested. These materials include three variations on a gypsum mixture to simulate Martian sandstone and a terrestrial lapilli tuff to substitute as a Martian tuffaceous sediment. The gypsum mixtures were identified as:

- 100 series: 80 percent gypsum sand, 20 percent calcium sulfate hemihydrate,

- 200 series: 50 percent gypsum sand, 50 percent calcium sulfate hemihydrate, and

- 300 series: 15-25 percent gypsum sand, 25-35 percent basalt sand, 50 percent calcium sulfate hemihydrate.

Percentages are by weight as measured before reacting with water. The gypsum sand was collected from the active dune field in White Sands National Monument, New Mexico. The sand was dried to ambient humidity ( 40 percent $\mathrm{RH}$ ), and the entire sample batch, $\sim 19 \mathrm{~L}$, was homogenized by mixing. The sample was passed through a $1 \mathrm{~mm}$ sieve, and only grains smaller than $1 \mathrm{~mm}$ in diameter were used to prepare the samples.

The basalt sand was prepared by pulverizing basalt using a hammer drill. The sample is from the basalt of Switzer Mesa, part of the San Francisco volcanic field in northern Arizona. This flow is recent, $5.82 \pm 0.34 \mathrm{Ma}$ (Damon and others, 1974), and minimally weathered. Identical to the gypsum sand, the basalt sand was dried to ambient humidity ( $\sim 40$ percent $\mathrm{RH})$, and the entire sample batch, $\sim 2 \mathrm{~L}$, was 
homogenized by mixing. The sample was passed through a $0.109 \mathrm{~mm}$ sieve, and only grains smaller than $0.109 \mathrm{~mm}$ in diameter were used to prepare the samples.

Samples were prepared by thoroughly mixing the gypsum sand, calcium sulfate hemihydrate powder, and basalt sand (if any). The mixture was passed through the $1 \mathrm{~mm}$ sieve twice during mixing in order to disaggregate the calcium sulfate hemihydrate powder and basalt sand. The sample mixture was then poured into a $25.4 \mathrm{~mm}$ ID, 3.2- mm-walled latex tube at increments of $9 \mathrm{~cm}^{3}$, and the sample was compressed to $1 \mathrm{MPa}$ after each increment was added. Additionally, $5 \mathrm{~mL}$ of deionized water was added into the latex tube after each sample increment was added and compressed. The water absorbed quickly into the gypsum mixture. This process was repeated until the sample reached a column length of $63.5 \mathrm{~mm}$. Thin Berea sandstone frits ( 20 percent porosity) were inserted on either end of the gypsum mix for stability and to act as pore fluid-permeable caps. The entire sample was submerged in roomtemperature deionized water for one hour, then air dried for at least one week. We refer to the resulting simulated rock as a "gypsum sandstone" based on grain size rather than mineralogy.

The lapilli tuff is from the northeast flank of North Menan Butte, which is part of the Menan Volcanic Complex in the Snake River Plain, eastern Idaho. Because the samples were too friable to be cored into cylinders, matching the geometry of the gypsum-rich samples, they were straight cut into prisms of roughly 19 by $19 \mathrm{~mm}$ square and $63.5 \mathrm{~mm}$ long. Thin, square wafers of Berea sandstone were placed on either end to ensure uniform distribution of the pore-pressure medium through the lapilli tuff. This rock sandwich was then held in placed between two stainless-steel adaptors with thin shrink tubing, and the entire assembly was then inserted into a length of latex tubing. The adaptors are shaped to transfer stress from the square cross-sectional rock to the round cross-sectional loading piston.

\section{Experimental Procedure}

\section{Axial Deformation Tests}

Because Martian sediments in the equatorial layered deposits currently are dry, all our simulated samples (in their latex jackets) were vacuum dried overnight at $50{ }^{\circ} \mathrm{C}$ to ensure a dry state. They were then attached to stainless-steel endplugs with a pore pressure inlet at the top. This assembly was tested in a standard triaxial apparatus at room temperature and effective stress, $\mathrm{P}_{\mathrm{e}}$ (defined as confining pressure, $\mathrm{P}_{\mathrm{c}}$, minus pore pressure, $\mathrm{P}_{\mathrm{p}}$ ) of $2,5,10$ and $15 \mathrm{MPa}$. A constant pore pressure of $\mathrm{P}_{\mathrm{p}}=10 \mathrm{MPa}$ argon gas was applied in all tests so that the samples remained dry at all times. The argon gas was contained in a closed system comprised of the sample, tubing, and computer-controlled pore-pressure generator. By assuming that the change in the sample matrix material is small compared to the change in pore volume, pore volume change can be determined by recording the volume change in the pore-pressure generator required to maintain constant pressure. At constant pore pressure, there is no correction required for the compressibility of argon in the volume measurements. Room temperature was controlled to \pm 0.2 degrees Celsius to minimize errors in pore volume due to thermal expansion of the argon gas.

The gypsum samples were deformed to $10 \mathrm{~mm}$ axial shortening at a rate of $0.000635 \mathrm{~mm} \mathrm{~s}^{-1}$ (equivalent to $0.001 \mathrm{~mm} \mathrm{~s}^{-1}$ along a $30^{\circ}$ inclined fault plane). Lapilli tuff samples were deformed to 8 mm axial shortening at the same rate. In most tests, the direction of the piston was reversed during the initial loading for a short time, causing stresses to drop, then reversed again to resume loading the sample. Initial application of axial stress results in a combination of elastic and inelastic sample shortening. Young's modulus depends on only the elastic strain resulting from a stress change. To isolate elastic strain, axial stress must be cycled a second time, following the initial loading. A greased Teflon shim, placed between the piston and the sample assembly, allowed easy lateral slip of the lower portion of the sample (if necessary) during deformation. Axial load was measured with an internal load cell. Because the load cell is calibrated to provide stress on a 25.4-mm diameter piston, axial load values of the rectangular lapilli tuff samples were adjusted by the ratio of the cross-sectional area of the 
samples to that of the piston. Axial shortening, confining pressure, and pore pressure were all measured at 1 sample $\mathrm{s}^{-1}$. The axial stress, confining pressure, and pore pressure have an accuracy of at least 0.03 $\mathrm{MPa}$.

\section{Hydrostatic Tests}

A separate series of tests was done on the four sample types under hydrostatic loading (no piston contact), with samples prepared as above. Effective pressure was increased slowly from $1 \mathrm{MPa}$ to values between 40 and $100 \mathrm{MPa}$, (depending on sample behavior), while pore pressure was maintained at 10 $\mathrm{MPa}$. Pore volume change in the sample was determined by recording the volume change in the pressure generator, as described above. Effective pressure cycling was done during these experiments to determine the bulk modulus of the samples.

\section{Strain Calculations}

Axial, volumetric, and transverse strain calculations are necessary to determine the physical constants of the rocks. We compute axial strain, $\varepsilon_{\mathrm{ax}}$, from the axial displacement measurement as follows. Axial strain is defined as

$$
\varepsilon_{a x}=\Delta L / L,
$$

where $L$ is sample length. However, axial displacement, $\Delta z$, measured outside of the pressure vessel, includes both sample shortening, $\Delta L$, and piston/machine shortening, $\Delta z_{m}$. The piston $/ \mathrm{machine}$ shortening is characterized by the machine stiffness $K_{m}$ and is determined in separate calibration tests on a steel sample according to

$$
\Delta \sigma_{1}=K_{m} \Delta z_{m}
$$

where $\sigma_{1}$ is axial stress. Then

$$
\varepsilon_{a x}=\left(\Delta z-\Delta \sigma_{l} / K_{m}\right) / L
$$

Axial displacement can be measured to \pm 0.5 micron, however, owing to the nature of the sample fabrication technique, the sample length can be measured only to $\pm 0.5 \mathrm{~mm}$. Consequently, changes in axial strain during a single experiment are known to a precision of $10^{-5}$, while absolute strain is only known to about \pm 2 percent.

Young's modulus, $E_{y}=\Delta \sigma_{l} / \Delta \varepsilon_{a x}$, is computed from the slope of an axial stress versus displacement plot as stress is cycled during elastic loading. The slope of the curve (in $\mathrm{MPa} / \mathrm{mm}$ ) gives the composite sample/machine stiffness, $K_{\text {total }}=\Delta \sigma_{1} / \Delta z$. Rearranging (3) and substituting for $\Delta z$ gives

$$
K_{\text {total }}=\Delta \sigma_{1} /\left(\Delta \varepsilon_{a x} L+\Delta \sigma_{l} / K_{m}\right) \text {. }
$$

Rearranging terms leads to the expression for Young's modulus:

$$
E_{y}=L\left(1 / K_{\text {total }}-1 / K_{m}\right)^{-1} \text {. }
$$

Porosity, $\phi$, is given by

$$
\phi=\left(V_{p o}+\Delta V_{p}\right) /\left(V_{o}+\Delta V_{p}\right),
$$

where $V_{p o}$ is the initial pore volume, $\Delta V p$ is the change in pore volume, and $V_{o}$ is the initial total sample volume. Assuming that the change in matrix volume is insignificant, we can express volumetric strain as $\varepsilon_{v o l}=\phi-\phi_{o}$, where $\phi_{o}$ is initial porosity. Because we do not know the initial porosity of these samples, we only relate changes in volumetric strain. Pore volume change can be measured to $\pm 0.0005 \mathrm{cc}$. However, because of uncertainty in the total sample volume, we estimate the volumetric strain accuracy to be \pm 2 percent. 
Finally, since

$$
\varepsilon_{v o l}=2 \varepsilon_{t r}+\varepsilon_{a x}
$$

where $\varepsilon_{t r}$ is the transverse strain, we obtain Poisson's ratio, $v=-\varepsilon_{t r} / \varepsilon_{a x}$ from the relation

$$
v=\left(1-\varepsilon_{v o l} / \varepsilon_{a x}\right) / 2 \text {. }
$$

\section{Results and Discussion}

Differential stress $\left(\sigma_{\Delta}=\sigma_{1}-P_{c}\right)$ as a function of axial displacement for the four sample types is shown in figure 1A-D. Differential stress increased with effective pressure in all cases as expected. The 100-series samples were the weakest of the gypsum sandstones because of the lesser percentage of cementing material. There was no discernable elastic portion of these deformation curves, that is, grain crushing and pore collapse occurred from the onset of loading. The 200- and 300-series samples were similar in strength, although 200 -series samples were stiffer during the elastic portions of the curves, indicating a higher Young's modulus than the 300-series samples. Many of the gypsum sandstone samples showed quasi-stable stress drops of up to $2 \mathrm{MPa}$ during deformation that were neither dynamic nor audible. These events had durations of a fraction of a second to a few seconds and may represent discrete compaction events. Some of the 200- and 300- series samples exhibited a peak differential stress with subsequent weakening, and in some cases, an eventual strength recovery at larger displacements. In contrast, the lapilli tuff samples all exhibited stable deformation, with smooth differential stress curves during axial shortening. The large stress drops occurring at 5, 10, and $15 \mathrm{MPa}$ were imposed to measure Young's modulus and should not be misinterpreted as stick-slip events.

All samples were examined after removal from the pressure vessel. The 100-series samples showed no visible fractures, with no barreling along the length of the sandstone cylinders in most cases. The sample at $10 \mathrm{MPa}$ showed a 2 percent increase in the diameter at the center of the sample. The 200and 300-series samples were both characterized by discrete fractures in almost every case, all at 30 degrees \pm 2 degrees from the axis of the rock cylinder. At $15 \mathrm{MPa}$, the 200 -series sample showed a 7 percent increase in diameter at the center (barrel) rather than a fracture. Axial stress values were not corrected for barreling, that is, axial stresses were computed assuming a 25.4-mm- diameter sample cross-section. We did not observe a trend of fault formation transitioning to compaction failure as a function of increasing effective pressure. More experiments would be needed to identify such a correlation. None of the lapilli tuff samples showed evidence of fracturing or barreling after pressurization. These samples deformed by crushing and pore collapse. Compaction bands would be hard to discern along the sides of any of these sample types, so we do not report on them here.

Changes in volumetric strain, calculated from the hydrostatic tests are shown in figure 2. Negative volumetric strain corresponds to decreasing sample volume, that is, the sample expelled argon gas. The gypsum sandstones show a more complex response to pressure than the lapilli tuff, with a shoulder to the strain curves at various effective pressures. The lapilli tuff is characterized by steadily decreasing rate of strain with pressure. Hysteresis loops during volumetric strain correspond to the effective pressure cycles used to measure bulk modulus. Because bulk modulus is a function of effective pressure, the pressure cycles were all performed in a similar pressure range $\left(\mathrm{P}_{\mathrm{e}}<25 \mathrm{MPa}\right)$ for a better comparison. After removal from the pressure vessel, all four sample types had a uniform exterior appearance, with no indication of discrete fracture formation.

An effort was made to differentiate between Mohr-Coulomb failure and shear- enhanced compaction following the procedure of Wong and Baud (1999) by characterizing the Q/P strength envelope of the materials. We start by plotting mean effective stress versus porosity change for both the deformation and hydrostatic tests (fig. 3) and then pick off points where the deformation tests diverge from the hydrostatic curve, designated as the critical stress states $C^{*}$ (for compaction) or C' (for 
dilation) (see Wong and Baud, 1999). At the two highest pressures of the 100-series samples, the deformation tests diverged immediately rather than following the hydrostatic curve during initial loading. That is, the samples immediately failed at a rate faster than predicted from hydrostatic loading tests, by shear-enhanced compaction, due to their weak cementation as observed in figure $1 \mathrm{~A}$. At $2 \mathrm{MPa}$, the reversal in direction along the porosity change axis indicated that the sample had started to compact, and then with further deformation, began to dilate. This behavior is common where effective pressures are low enough that the sandstone grains can ride over one another, causing a volume expansion, rather than deform by grain crushing and porosity loss alone. The equivalent plots for the 200 -series, 300 series, and lapilli tuff samples were not as systematic and did not follow the trend of the hydrostatic curves during initial loading. However, dilation was observed at the lower pressures and compaction was observed at higher pressures for all three sample types. More extensive tests, including detailed microstructural analysis, would be needed to properly distinguish differences in micromechanical deformation mode in these samples.

Nonetheless, physical properties of the samples are straightforward to calculate. For instance, Young's modulus, $E_{y}$, is shown for the 200-series, 300-series, and lapilli tuff samples in figure 4. (The 100 -series samples were not pressure cycled, so Young's modulus could not be determined). Young's modulus values in figure 4 generally increased linearly with effective pressure, and all fell within the range of 2,000-9,000 MPa. The 200-series samples had distinctly higher values of $E_{y}$ than the 300-series samples, showing that the addition of basaltic dust to the 300-series samples lowered the modulus considerably, even though both series had similar pressure dependence $\left(\Delta E_{y} / \Delta P_{e}\right)$ of 340-350 MPa per $\mathrm{MPa}$ effective pressure (note the parallel trend lines). Lapilli tuff samples had the lowest Young's modulus and exhibited less pressure sensitivity of $E_{y}$, at $197 \mathrm{MPa}$ per MPa effective pressure. Error bars in figure 4 are $\pm 5 \%$.

Four of the experiments lent themselves to calculations of Poisson's ratio-two series 300 samples and two lapilli tuff samples (fig. 5). Poisson's ratio is a measure of the lateral expansion of a material from a given lengthwise compression. Values ranged from 0.18 to 0.29 . Error bars indicate $1 \sigma$ values in figure 5. Poisson's ratio measurements would be possible on the complete suite of samples if the experiments were done at a slower deformation rate, so that pore-volume response (requiring argon to diffuse in or out of the sample) was better linked to the changing stresses.

Bulk modulus (fig. 6) was calculated from the volume response during the pressure cycle loops of the hydrostatic tests shown in figure 2. During the reloading of pressure, we determined the slope of the volumetric strain versus effective pressure. Bulk modulus is the inverse of this number. In figure 6, values are plotted at the mean effective pressure during the pressure cycle. Bulk modulus was variable, ranging from around 2,500 to 4,500 $\mathrm{MPa}$ for the four sample types. The 100-series sample (low cementation) had the lowest value, whereas the 200-series sample (more cementation and no basaltic dust), had a considerably higher value than all the others. The addition of basaltic dust may be a factor in the 300 -series value compared to the 200 -series value (as well as the difference in effective pressure). Error bars $( \pm 2 \%)$ are smaller than the data points. Data for all the physical properties plotted in figures 4-6 can be found in table 1. 
Table 1. Physical Properties of Samples

\begin{tabular}{|c|c|c|c|c|}
\hline Series & $\mathrm{Pe}^{*}(\mathrm{MPa})$ & $\begin{array}{l}\text { Young's Modulus } \\
(\mathrm{Ey}, \mathrm{MPa})\end{array}$ & Poisson's Ratio, $v$ & Bulk Modulus (MPa) \\
\hline 100 & $13-25$ & & & 2470 \\
\hline 200 & 2 & 4460 & & \\
\hline 200 & 5 & 6160 & & \\
\hline 200 & 10 & 9000 & & \\
\hline 200 & 15 & 8650 & & \\
\hline 200 & $16-22$ & & & 4440 \\
\hline 300 & 2 & 3440 & & \\
\hline 300 & 5 & 3940 & & \\
\hline 300 & 10 & 6230 & $0.27 \pm 0.04$ & \\
\hline 300 & 15 & 7770 & $0.29 \pm 0.07$ & \\
\hline 300 & $4-11$ & & & 2970 \\
\hline tuff & 5 & 2120 & & \\
\hline tuff & 10 & 3130 & $0.28 \pm 0.06$ & \\
\hline tuff & 15 & 4090 & $0.18 \pm 0.06$ & \\
\hline tuff & $12-19$ & & & 3100 \\
\hline
\end{tabular}

*Bulk Modulus was measured over a range of pressures.

\section{Conclusions}

We have measured the strength of simulated Mars materials under a range of pressure conditions in a dry state. Strength increased with increasing effective confining pressure in all cases. Several types of deformation behavior were observed, including stable sliding and repeated, small, quasi-stable stress drops. The 100-series samples showed shear-enhanced compaction as soon as deviatoric stress was applied, owing to their low degree of cementation. All the gypsum-rich sandstones were comparatively weak relative to silica-rich sandstone types (for example, Wong and others, 1997), because gypsum is inherently weaker than quartz. Peak differential stress was generally less than $40 \mathrm{MPa}$ even after $10 \mathrm{~mm}$ of axial shortening. Like the 100-series samples, the lapilli tuff samples run at higher effective pressures, continued to strain harden for the entire experiment, and never reached a steady strength. In all cases, it was difficult to differentiate between Mohr-Coulomb failure and shear-enhanced compaction following the procedure of Wong and Baud, 1999, although discrete failure planes, all at 30 degrees \pm 2 degrees, were apparent in many of the 200- and 300-series samples.

Physical properties such as Young's modulus, Poisson's ratio, and bulk modulus, were readily obtainable and reflected the nature of these weak gypsum-rich sandstones and volcaniclastic rocks (see, for example, Lama and Vutukuri, 1978, for a comparison of other rock types). Young's modulus was dependent on composition, and increased linearly with effective confining pressure. Values ranged from 2,000 to 9,000 MPa for the four sample types over the pressure range tested. Poisson's ratio, measured for the 300-series sandstones and the lapilli tuff, ranged from 0.18 to 0.29 . The bulk modulus of the four samples, measured at effective confining pressures below $20 \mathrm{MPa}$, ranged from 2,470 to 4,440 $\mathrm{MPa}$. 


\section{References}

Antonellini, M., and Aydin, A., 1994, Effect of faulting on fluid flow in porous sandstones;

petrophysical properties: American Association of Petroleum Geologists Bulletin, v. 78, p. 355-377.

Antonellini, M., and Aydin, A., 1995, Effect of faulting on fluid flow in porous sandstones; geometry and special distribution: American Association of Petroleum Geologists Bulletin, v. 79, p. 642-671.

Damon, P.E., Shafiqullah, M., and Leventhal, J.S., 1974, K-Ar chronology for the San Francisco volcanic field and rate of erosion of the Little Colorado River, in Karlstrom, T.N.V., Swann, G.A., and Eastwood, R.L., eds., Geology of northern Arizona, Part I-Regional studies: Geological Society of America, Rocky Mountain Section Meeting, Flagstaff, Ariz., Guidebook, p. 221-235.

Lama, R.D., and Vutukuri, V.S., 1978, Handbook on mechanical properties of rocks: Series on Rock and Soil Mechanics, v. 3, no. 1, Trans Tech Publications, Clausthal, Germany.

Murchie, S., Roach, L., Seelos, F., Milliken, R., Mustard, J., Arvidson, R., Wiseman, S., Lichtenberg, K., Andrews-Hanna, J., and Bishop, J., 2009, Evidence for the origin of layered deposits in Candor Chasma, Mars, from mineral composition and hydrologic modeling: Journal of Geophysical Research, v. 114, p. E00D05.

Ogilvie, S.R., and Glover, P.W.J., 2001, The petrophysical properties of deformation bands in relation to their microstructure: Earth Planet Science. Letters, v. 193, p. 129-142, doi:10.1016/S0012821X(01)00492-7.

Squyres, S.W., Arvidson, R.E., Bell, J.F., Calef, F., Clark, B.C., Cohen, B.A., Crumpler, L.A., de Souza, P.A., Farrand, W.H., Gellert, R., Grant, J., Herkenhoff, K.E., Hurowitz, J.A., Johnson, J.R., Jolliff, B.L., Knoll, A.H., Li, R., McLennan, S.M., Ming, D.W., Mittlefehldt, D.W., Parker, T.J., Paulsen, G., Rice, M.S., Ruff, S.W., Schröder, C., Yen, A.S., and Zacny, K., 2012, Ancient impact and aqueous processes at Endeavour Crater, Mars: Science, v. 336, no. 6081, p. 570-576.

Taylor, W.L., and Pollard, D.D., 2000, Estimation of in situ permeability of deformation bands in porous sandstone, Valley of Fire, Nevada: Water Resources. Research, v. 36, p. 2595-2606, doi:10.1029/2000WR900120.

Wong, T.F., David. C., and Zhu, W., 1997, The transition from brittle faulting to cataclastic flow in porous sandstones-Mechanical deformation: Journal of Geophysical Research, v. 102, p. 3009-3025. Wong, T.F., and Baud, P., 1999, Mechanical compaction of porous sandstone: Oil and Gas Science and Technology, v. 54, no. 6, p. 715-727.

Zimbelman, J.R., and Scheidt, S.P., 2012, Hesperian age for Western Medusae Fossae Formation, Mars: Science, v. 336, no. 6089, p. 1683, doi: 10.1126/science.1221094. 


\section{Figures}
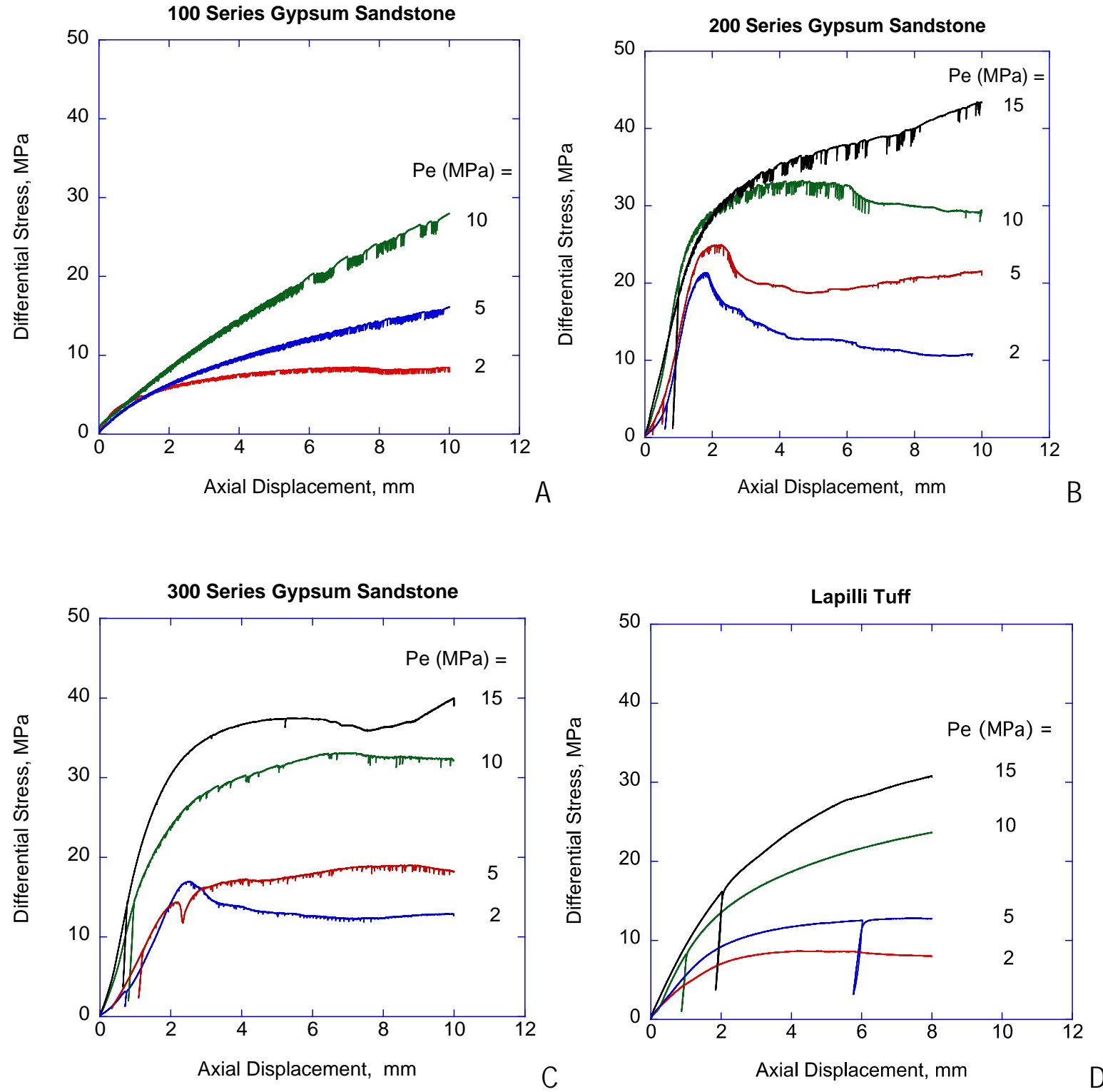

Figure 1 Differential stress as a function of axial displacement for A, 100-series samples; B, 200-series samples; $C, 300$-series samples; and D, lapilli tuff. Effective pressures for each experiment are shown at right. Pressure cycling during loading in 1B-1D was conducted to determine Young's modulus. 


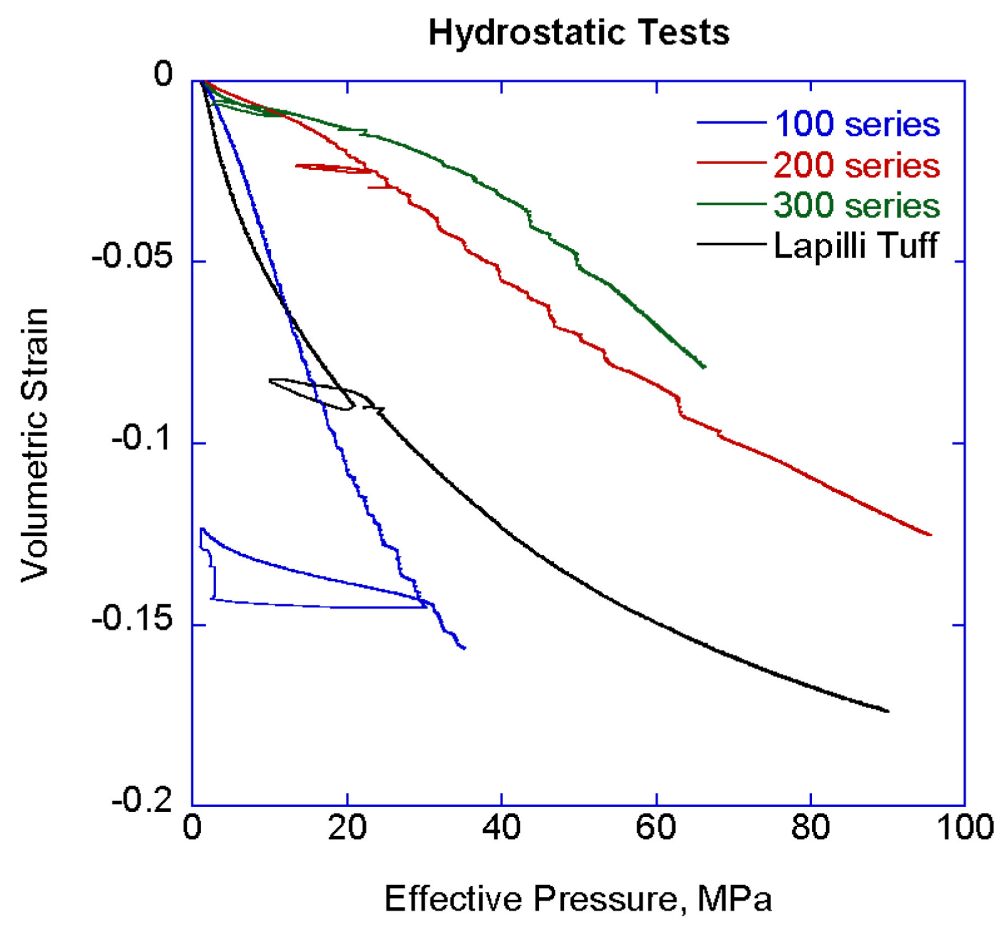

Figure 2. Volumetric strain as a function of effective pressure for the four sample types. Pressure cycling (for bulk modulus calculations) appears as loops. Negative slope values indicate that the sample compressed (porosity decreased) with applied pressure.

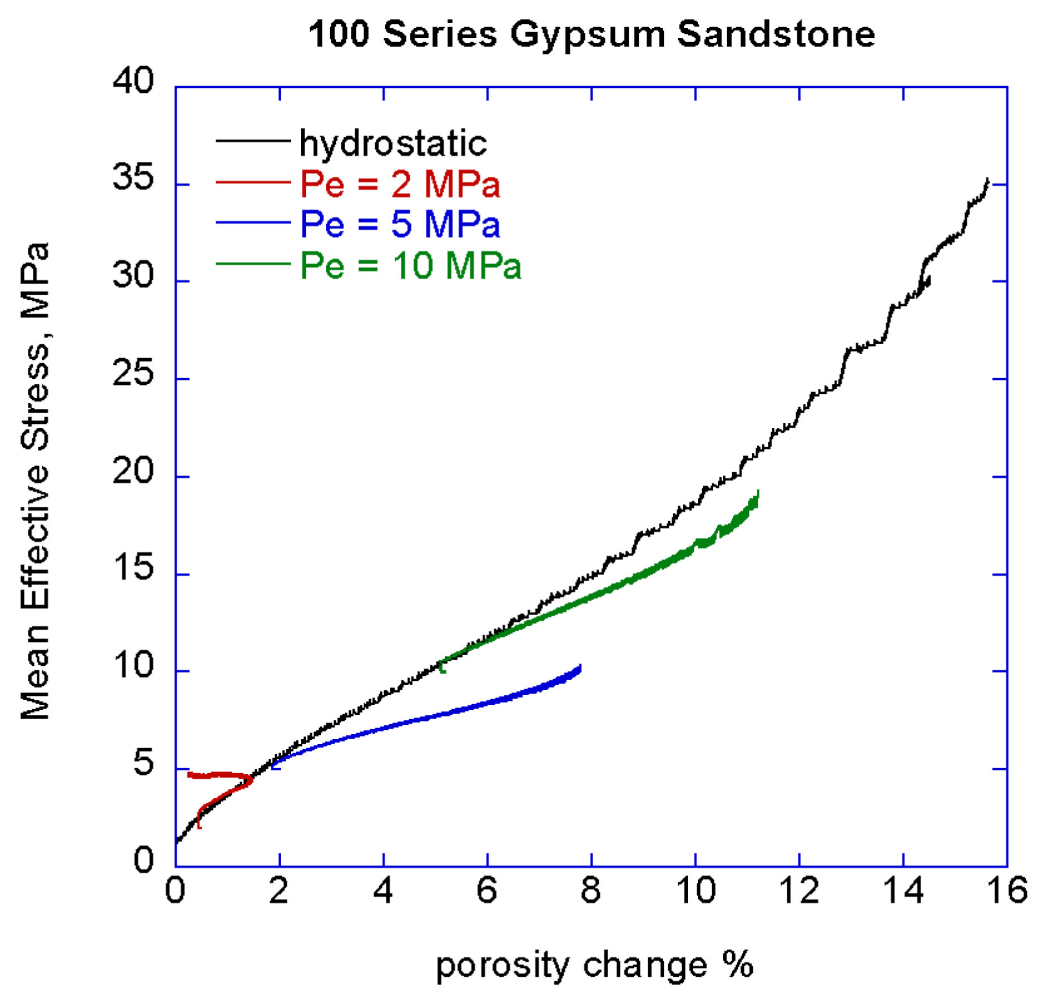

Figure 3. Mean effective stress as a function of porosity change for both deformation tests and hydrostatic loading of the 100 series samples. Porosity change (shown as positive with increasing pressure) is equivalent to the volumetric strain (negative with increasing pressure) shown in Figure 2. 


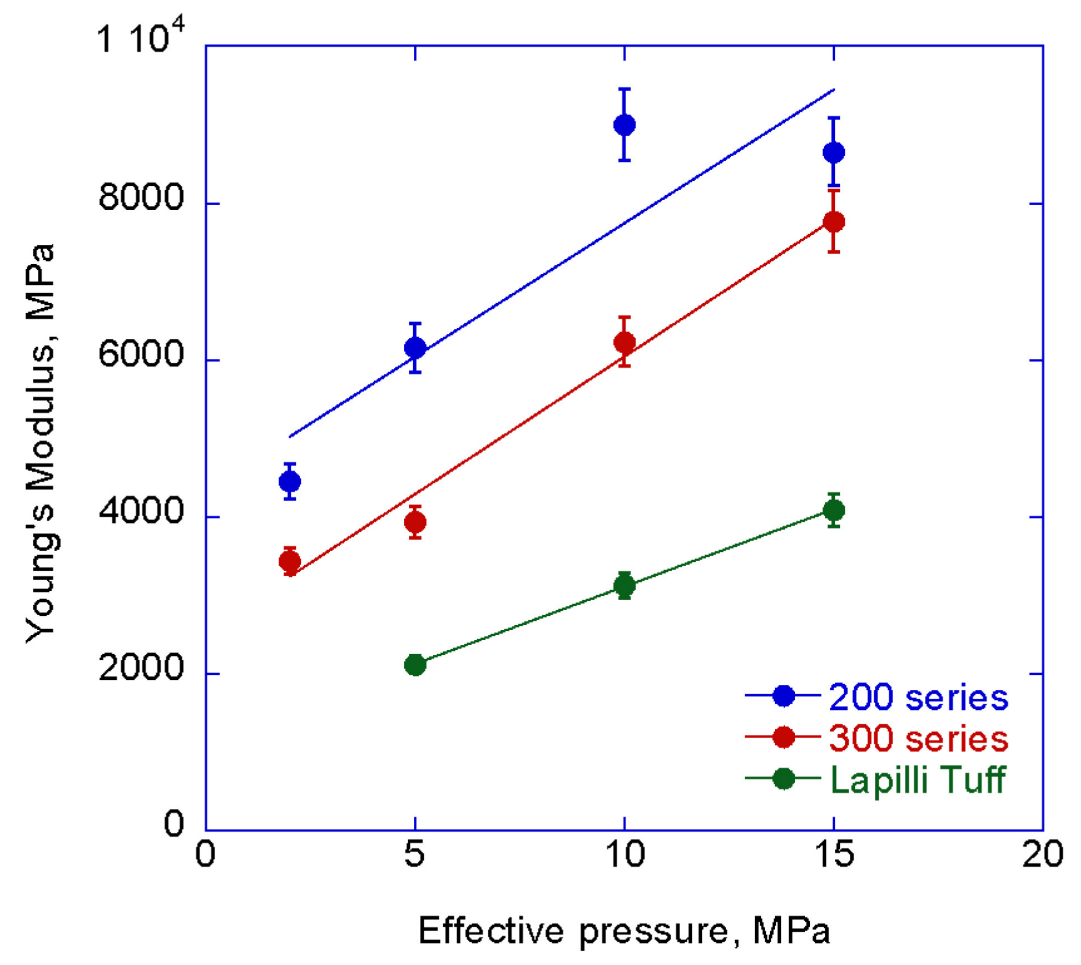

Figure 4. Young's Modulus as a function of effective pressure for three sample types. Young's modulus was not tested on the 100 series samples. Error bars $\pm 5 \%$.

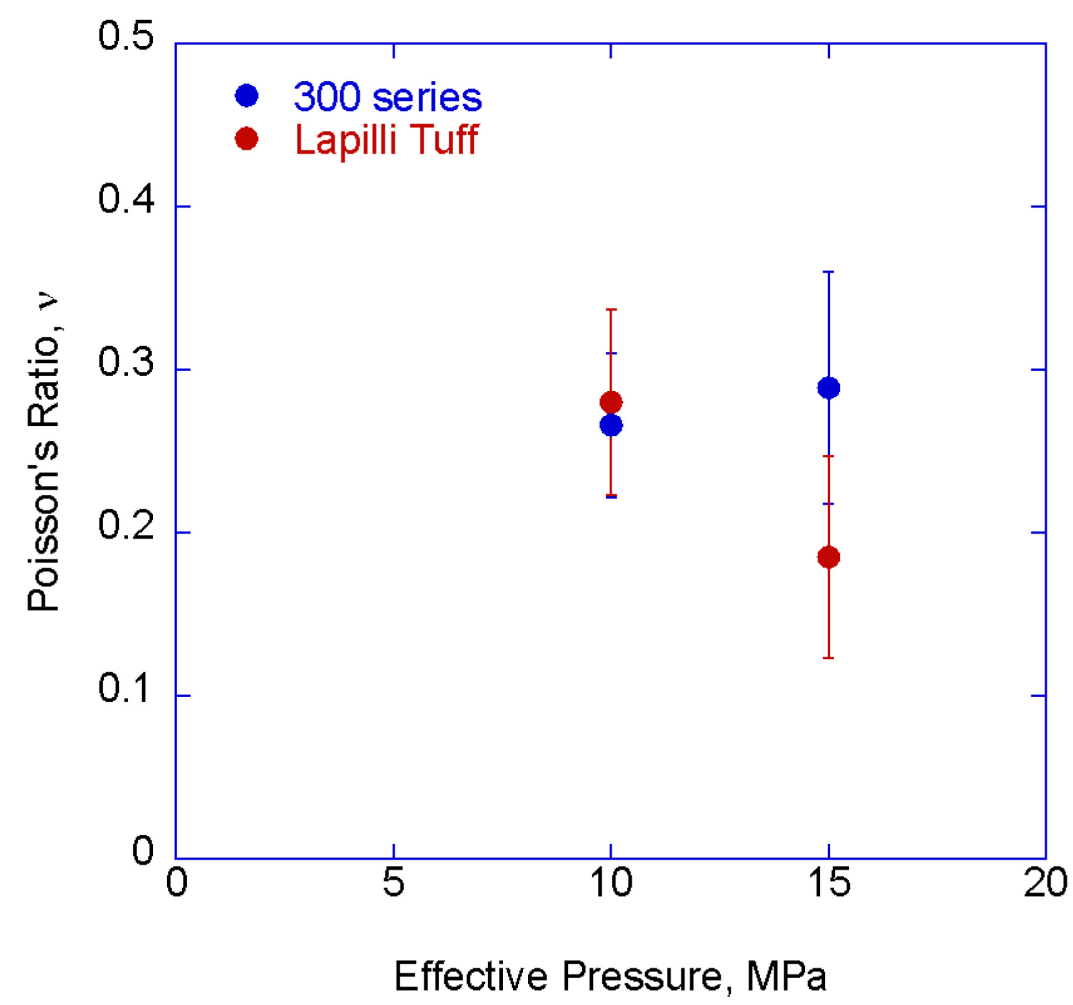

Figure 5. Poisson's Ratio for selected 300 series and lapilli tuff samples. Poisson's ratio is a measure of the lateral expansion of a material from a given lengthwise compression. Error bars $\pm 1 \sigma$. 


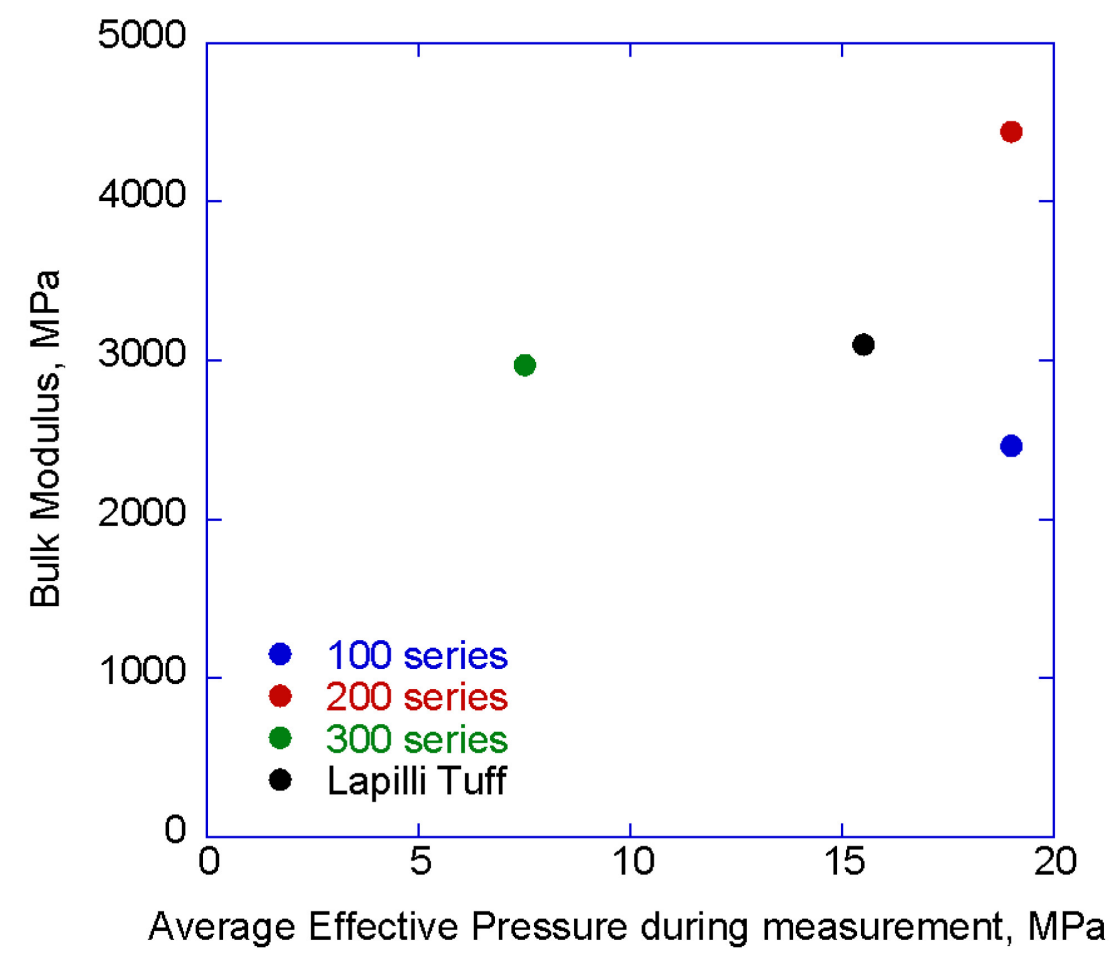

Figure 6. Bulk Modulus of the four sample types as a function of the average effective pressure during the measurement. Error $\pm 2 \%$ (smaller than the data points). 


\section{黄}

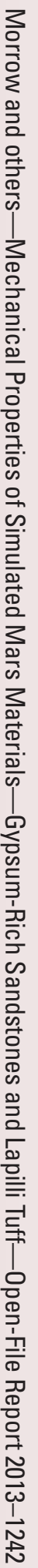

